\title{
Hydrous cerium oxides coated glass fiber for efficient and long-lasting arsenic removal from drinking water
}

\author{
Ronghui $\mathrm{LI}^{a}$, Weiyi YANG ${ }^{b}$, Shuang $\mathrm{GAO}^{b}$, Jianku SHANG ${ }^{c}$, Qi LI ${ }^{b, *}$ \\ ${ }^{a}$ School of Gemology and Material Technology, Hebei GEO University, Shijiazhuang 050031, China \\ ${ }^{b}$ Key Laboratory of Advanced Technologies of Materials (Ministry of Education), School of Materials \\ Science and Engineering, Southwest Jiaotong University, Chengdu 610031, China \\ ${ }^{c}$ Shenyang National Laboratory for Materials Science, Institute of Metal Research, \\ Chinese Academy of Sciences, Shenyang 110016, China
}

Received: July 17, 2020; Revised: October 29, 2020; Accepted: October 30, 2020

(C) The Author(s) 2020.

\begin{abstract}
A novel arsenic adsorbent with hydrous cerium oxides coated on glass fiber cloth (HCO/GFC) was synthesized. The HCO/GFC adsorbents were rolled into a cartridge for arsenic removal test. Due to the large pores between the glass fibers, the arsenic polluted water can flow through easily. The arsenic removal performance was evaluated by testing the equilibrium adsorption isotherm, adsorption kinetics, and packed-bed operation. The $\mathrm{pH}$ effects on arsenic removal were conducted. The test results show that $\mathrm{HCO} / \mathrm{GFC}$ filter has high As(V) and As(III) removal capacity even at low equilibrium concentration. The more toxic As(III) in water can be easily removed within a wide range of solution $\mathrm{pH}$ without pre-treatment. Arsenic contaminated ground-water from Yangzong Lake (China) was used in the column test. At typical breakthrough conditions (the empty bed contact time, $\mathrm{EBCT}=2 \mathrm{~min}$ ), arsenic researched breakthrough at over 24,000 bed volumes (World Health Organization (WHO) suggested that the maximum contaminant level (MCL) for arsenic in drinking water is $10 \mathrm{mg} / \mathrm{L}$ ). The Ce content in the treated water was lower than $5 \mathrm{ppb}$ during the column test, which showed that cerium did not leach from the HCO/GFC material into the treated water. The relationship between dosage of adsorbents and the adsorption kinetic model was also clarified, which suggested that the pseudo second order model could fit the kinetic experimental data better when the adsorbent loading was relatively low, and the pseudo first order model could fit the kinetic experimental data better when the adsorbent loading amount was relatively high.

Keywords: hydrous cerium oxide (HCO); glass fiber cloth (GFC); column test; adsorption kinetics; adsorption mechanism
\end{abstract}

\section{Introduction}

Arsenic contamination of water bodies (ground/surface

* Corresponding author.

E-mail: qiliuiuc@outlook.com water) could cause many human health problems, such as skin, lung, bladder, and kidney cancers as well as the neurological and cognitive dysfunction in children [1]. The World Health Organization (WHO) had classified arsenic as a carcinogen and recommended that the maximum contaminant level (MCL) for arsenic in 
drinking water should not be over $10 \mu \mathrm{g} / \mathrm{L}$ [2]. Thus, it is important to remove excess arsenic species effectively from drinking water to guarantee the health of millions of people living near arsenic contaminated water bodies.

Several arsenic removal techniques have been established for arsenic removal from contaminated water sources, including precipitation/co-precipitation, ion-exchange, and adsorption [3]. Among them, the adsorption process is generally considered as a simple and cost-effective process to remove arsenic from drinking water when its contamination level is not very high [4]. With the rapid development of the synthesis and application of nanomaterials, various nanoadsorbents for arsenic removal had recently been developed, including hydrous $\mathrm{TiO}_{2}$ nanoparticles [5], $\mathrm{Fe}_{2} \mathrm{O}_{3}$ nanoparticles [6], $\mathrm{Fe}_{3} \mathrm{O}_{4}$ nanoparticles [7], $\mathrm{CuO}$ nanoparticles [8], and nanostructured $\mathrm{ZrO}_{2}$ sphere [9], which demonstrated promising arsenic removal performances from drinking water because of their large surface areas and suitable surface properties derived from their nanoscale nature [10]. However, most nanoadsorbents still have two major limitations which make it difficult for their applications in drinking water treatment practices. First, it is difficult to separate and reuse these nanoabsorbents after they are dispersed in arsenic contaminated water, and it is not feasible to use them in a fixed-bed or flow-through system due to the high particle attrition rate and the high pressure drop. Furthermore, some commonly used nanoadsorbents, for example nano-ferric oxides, have a leaching problem especially when the water $\mathrm{pH}$ varies, which could cause secondary pollution to drinking water.

Cerium oxide $\left(\mathrm{CeO}_{2}\right)$ is the most abundant and least expensive rare earth metal oxide. Due to its particular functionalities, it has been extensively investigated for various technical applications [11-13]. It possesses the lowest solubility against acid among the rare earth metal oxides, and does not elute during water treatment [14]. Thus, it had been studied as a potential adsorbent for the removal of various hazardous substances from water, including fluoride [15], bichromate [16], and arsenic species [17-19]. Although hydrous $\mathrm{CeO}_{2}$ nanoparticles had demonstrated a superior arsenic adsorption performance for both $\mathrm{As}(\mathrm{III})$ and $\mathrm{As}(\mathrm{V})$ especially for drinking water treatment [20], their application in real practice is still rare because of their difficult separation from treated water and unfitness for fixed-bed or flow-through treatment systems from their nanoscale feature as other nanoadsorbents. One feasible solution for this problem is to immobilize nano-sized $\mathrm{CeO}_{2}$ onto macroscopic porous matrixes, which could be easily used in fixed-bed or flow-through treatment systems and avoid the nanomaterial separation issue. Several macroscopic porous matrixes had been developed for the loading of $\mathrm{CeO}_{2}$ nanoparticles for arsenic removal, including porous resin [21], silica monolith [22], porous ceramic foam $[23,24]$, and polymeric anion exchanger [25]. However, their synthesis processes were generally complex and time consuming, and they were quite expensive to be used for arsenic removal practices.

In this study, the glass fiber cloth (GFC) was chosen as the macroscopic porous matrix for hydrous $\mathrm{CeO}_{2}$ nanoparticle loading to create a highly efficient, long-lasting adsorbent (HCO/GFC) for the removal of arsenic species from drinking water. The GFC matrix has the advantages of low cost, nontoxicity, and abundance of three-dimensional, interconnected large macropores which could facilitate both the flow-through of arsenic contaminated water with low pressure drop and their efficient contact with $\mathrm{CeO}_{2}$ nanoparticles loaded on GFC. Furthermore, the nonwoven GFC used in this study was not fragile and it had a good flexibility for its assembly into a cartridge for being used in the flow-through apparatus. The $\mathrm{HCO} / \mathrm{GFC}$ adsorbent demonstrated a good arsenic adsorption performance for both $\mathrm{As}(\mathrm{III})$ and $\mathrm{As}(\mathrm{V})$ in water, especially at low equilibrium arsenic concentrations, which suggested its application potential for drinking water treatment. The kinetics study demonstrated that the pseudo second order model could fit the kinetic experimental data better when the adsorbent loading was relatively low, whereas the pseudo first order model could fit the kinetic experimental data better when the adsorbent loading amount was relatively high. It could be easily rolled into cartridges for the use in the fixed-bed water treatment apparatus, which demonstrated a good arsenic removal performance in both lab-prepared and natural water samples with a large arsenic breakthrough bed volume, high regeneration capability, and good stability.

\section{Experimental}

\section{1 Materials and chemicals}

All the chemicals used in the synthesis process were of analytical reagent grade. $\mathrm{Ce}\left(\mathrm{NO}_{3}\right)_{3} \cdot 6 \mathrm{H}_{2} \mathrm{O}$ and $\mathrm{NaOH}$ 
(Sinopharm Chemical Reagent Corporation, Shanghai, China) were used to synthesize $\mathrm{HCO}$ nanoparticles in ethanol solution. Sodium (meta) arsenite $\left(\mathrm{NaAsO}_{2}\right.$, Shanghai Tian Ji Chemical Institute, Shanghai, China) and sodium arsenate heptahydrate $\left(\mathrm{NaH}_{2} \mathrm{AsO}_{4} \cdot 7 \mathrm{H}_{2} \mathrm{O}\right.$, Fluka, USA) was used to prepare As(III) and As(V) stock solution. Concentrated hydrochloride acid $(\mathrm{HCl}, 32 \%-$ 38\%, Tianda Chemical Reagents Factory, Tianjin, China) was used to stabilize the arsenic species after treatment. As(III) and As(V) solutions used in the batch experiments were obtained by diluting the As(III) and As(V) stock solution to desired concentration with de-ionized (DI) water. The GFC was a non-woven fiber glass mat (Craneglas230, 0.015 nominal, fiber diameter of $16 \mu \mathrm{m}$ ) made by CRANE \& CO (Stamford, CT, USA).

\section{2 Synthesis of $\mathrm{CeO}_{2}$ nanoparticle-loaded GFC}

Hydrous $\mathrm{CeO}_{2}$ nanoparticles were synthesized by the following process. $0.02 \mathrm{~mol} \mathrm{NaOH}$ powder was dissolved in $100 \mathrm{~mL}$ absolute ethanol to prepare $0.2 \mathrm{M} \mathrm{NaOH} /$ ethanol solution. $0.005 \mathrm{~mol} \mathrm{Ce}\left(\mathrm{NO}_{3}\right)_{3} \cdot 6 \mathrm{H}_{2} \mathrm{O}$ powder was dissolved in $100 \mathrm{~mL}$ absolute ethanol to prepare $0.05 \mathrm{M} \mathrm{Ce}\left(\mathrm{NO}_{3}\right)_{3} /$ ethanol solution. The $\mathrm{NaOH} /$ ethanol solution was then added into the $\mathrm{Ce}\left(\mathrm{NO}_{3}\right)_{3} /$ ethanol solution at room temperature under vigorous stirring. With the mix of these two solutions, dark brown colloidal precipitates immediately formed. After being stirred continuously in air, the color of these colloidal precipitates changed from dark brown to gray yellow, and finally to bright yellow within $20 \mathrm{~min}$. During this process, the main valence of cerium in precipitation changed from +3 to +4 , and the cerium hydroxides transferred to hydrous $\mathrm{CeO}_{2}$. Finally, these precipitates were collected by the centrifugation, washed with DI water and absolute ethanol for several times, and dried in air at $100{ }^{\circ} \mathrm{C}$ for $12 \mathrm{~h}$ to obtain HCO nanoparticles.

To load hydrous $\mathrm{CeO}_{2}$ nanoparticles on $\mathrm{GFC}$, a piece of GFC was firstly dipped into $15 \% \mathrm{NH}_{4} \mathrm{OH}$ aqueous solution for 3 min to clean the glass fiber surface and improve the adhesion between $\mathrm{CeO}_{2}$ and glass fiber. After drying at $85{ }^{\circ} \mathrm{C}$ for $5 \mathrm{~min}$, it was immersed into an aqueous solution of $\mathrm{Ce}\left(\mathrm{NO}_{3}\right)_{3} \cdot 6 \mathrm{H}_{2} \mathrm{O}(0.05 \mathrm{~mol}$ in $100 \mathrm{~mL} \mathrm{H}_{2} \mathrm{O}$ ) for $3 \mathrm{~min}$. The above process was repeated for two more times, and the obtained sample was then dried at $90{ }^{\circ} \mathrm{C}$ for $5 \mathrm{~min}$, and washed with DI water for several times to removal $\mathrm{NH}_{4}^{+}, \mathrm{NO}_{3}^{-}$, and $\mathrm{CeO}_{2}$ nanoparticles that were not firmly loaded onto the GFC to obtain the desired $\mathrm{HCO} / \mathrm{GFC}$ adsorbent sample. To prepare the HCO/GFC filter for a flow-through apparatus with the down flow design as shown in Fig. 1, the $\mathrm{HCO} / \mathrm{GFC}$ adsorbent was rolled into a cartridge (with the inner radius of $30 \mathrm{~mm}$ and volume of $100 \mathrm{~mL}$ ) and put into a glass tube with two ends sealed to avoid any potential leakage of glass fibers. The loading amount percentage of HCO on GFC was calculated by Eq. (1):

$$
\text { Loading amount }(\%)=\frac{W_{2}-W_{1}}{W_{2}}
$$

where $W_{1}$ is the weight of pure GFC and $W_{2}$ is the weight of GFC after the immobilization of HCO. The loading amount percentage of $\mathrm{HCO} / \mathrm{GFC}$ adsorbent in this study was determined at $\sim 18.3 \%$.

\section{3 Characterization of the HCO/GFC adsorbent}

The morphology of the HCO/GFC adsorbent was examined by field emission scanning electron microscopy (FESEM). The crystal structure of nano-HCO nanoparticles was analyzed by X-ray powder diffractometer (D/MAX2004-X-ray Rigaku Corporation, Tokyo, Japan). The surface element composition and chemical states of the samples were examined by X-ray photoelectron spectroscopy (XPS) measurements (Thermo Fisher Scientific Inc., Waltham, MA, USA). The isoelectric point of $\mathrm{HCO}$ nanoparticles was measured with electrophoretic spectroscopy (JS84H, Shanghai Zhongchen Digital Instrument Co., Ltd., Shanghai, China).

\section{4 Arsenic adsorption methods}

All the arsenic adsorption experiments were conducted at $25{ }^{\circ} \mathrm{C}$ and under common day-light illumination condition. In order to evaluate the intrinsic adsorption capacity of the hydrous $\mathrm{CeO}_{2}$ nanoparticle, the $\mathrm{As}$ (III) and $\mathrm{As}(\mathrm{V})$ equilibrium adsorption isotherm study was carried out. The hydrous $\mathrm{CeO}_{2}$ nanoparticles with the same material loadings $(0.02 \mathrm{~g} / \mathrm{L})$ were added into the arsenic solutions with various initial concentrations (from $100 \mu \mathrm{g} / \mathrm{L}$ to $5 \mathrm{mg} / \mathrm{L}$ ) respectively and the suspensions were stirred magnetically for $24 \mathrm{~h}$ to disperse the

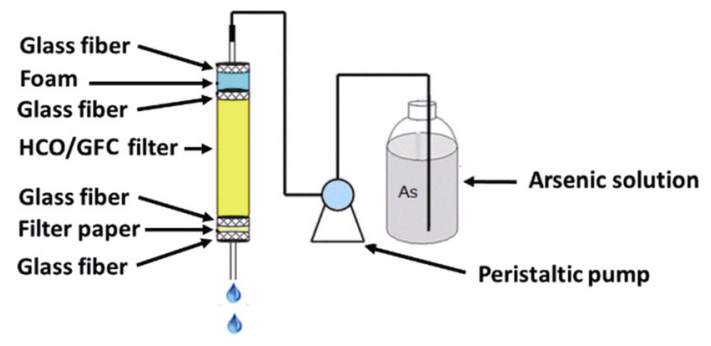

Fig. 1 Schematic diagram of the HCO/GFC filter cartridge and the column test setup. 
samples. After appropriate time intervals, the sample was recovered by centrifugation at $2500 \mathrm{rpm}$ for $10 \mathrm{~min}$. The adsorption capacity at different equilibrium arsenic concentrations could then be calculated from the difference between the initial and the equilibrium concentrations. The arsenic removal kinetics of GFC immobilized with $\mathrm{HCO}$ nanoparticles was also investigated.

The column test was carried out using $\mathrm{HCO} / \mathrm{GFC}$ cartridge described in Section 2.2. The setup contained a cartridge pump and a pre-prepared stock arsenic solution with DI water or arsenic contaminated ground-water. The flow rate of the arsenic solution was controlled by the pump. The arsenic concentration in the effluent was monitored by a atomic fluorescence spectrophotometer (AFS-9800, Beijing KeChuangHaiGuang Instrument Inc., Beijing, China). The schematic diagram of the column test for arsenic removal is shown in Fig. 1. The empty bed volume of the $\mathrm{HCO} / \mathrm{GFC}$ adsorbent is $100 \mathrm{~mL}$. The weight percentage of $\mathrm{HCO}$ is $18.3 \%$ of the total filter. Both lab prepared (the initial As(III) concentration was $\sim 84 \mu \mathrm{g} / \mathrm{L}$ and the initial $\mathrm{As}(\mathrm{V})$ concentration was $\sim 89 \mu \mathrm{g} / \mathrm{L}$ ) and natural arsenic polluted water was tested in this study. The natural water was collected from ground-water of Yangzong Lake (China). The total arsenic concentration of natural water was $65 \mathrm{ppb}$, in which As(III) accounted for about $30 \%$. The $\mathrm{pH}$ of the natural water was about 7.8. The water quality data was presented in Table 1 .

\section{Results and discussion}

\section{1 Characterization of the HCO/GFC adsorbent}

Figure 2 shows the X-ray diffraction (XRD) analysis result of the obtained $\mathrm{HCO} / \mathrm{GFC}$ adsorbent. The XRD peaks of cubic fluorite $\mathrm{CeO}_{2}$ phase (JCPDS Number: 34-0394) could be observed in the XRD pattern, which

\begin{tabular}{|c|c|c|c|}
\hline Ion species & Concentration $(\mathrm{mg} / \mathrm{L})$ & Ion species & Concentration $(\mathrm{mg} / \mathrm{L})$ \\
\hline $\mathrm{F}^{-}$ & 0.54 & $\mathrm{~K}^{+}$ & 5 \\
\hline $\mathrm{Cl}^{-}$ & 5.77 & $\mathrm{Ca}^{2+}$ & 24 \\
\hline $\mathrm{NO}_{3}^{-}$ & 4.78 & $\mathrm{Mg}^{2+}$ & 29 \\
\hline $\mathrm{HSO}_{4}^{-}$ & 365.73 & $\mathrm{Fe}^{3+}$ & $<1$ \\
\hline $\mathrm{HCO}_{3}^{-}$ & 339.31 & $\mathrm{As}(\mathrm{III})$ & 0.021 \\
\hline $\mathrm{Na}^{+}$ & 170 & $\operatorname{As}(\mathrm{V})$ & 0.044 \\
\hline
\end{tabular}

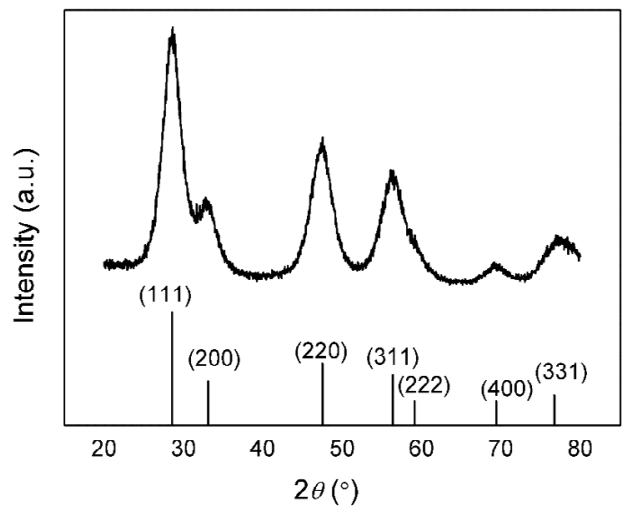

Fig. 2 XRD patterns of the HCO/GFC adsorbent.

clearly demonstrated that $\mathrm{CeO}_{2}$ nanoparticles were successfully loaded on the GFC. The crystallite size $(D)$ of $\mathrm{CeO}_{2}$ nanoparticles was determined at $\sim 4 \mathrm{~nm}$ from the strongest XRD peak (111) by the Scherrer's formula:

$$
D=0.9 \lambda /(\beta \cos \theta)
$$

where $\lambda$ is the average wavelength of the $\mathrm{X}$-ray radiation, $\beta$ is the line-width at half-maximum peak position, and $\theta$ is the diffracting angle.

Figures 3(a)-3(c) show the FESEM observation results of the $\mathrm{HCO} / \mathrm{GFC}$ adsorbent. Figure 3(a) shows the morphology of $\mathrm{HCO} / \mathrm{GFC}$ adsorbents, which composed of GFC as a skeleton support and hydrous $\mathrm{CeO}_{2}$ particles as the active sites. Figure 3(b) clearly demonstrated that hydrous $\mathrm{CeO}_{2}$ nanoparticles were well dispersed onto the GFC. Because of the large macropores between glass fibers, the arsenic contaminated water could flow through the $\mathrm{HCO} / \mathrm{GFC}$ adsorbent easily with low pressure drop. Figure 3(c) with a higher magnification demonstrates that these hydrous $\mathrm{CeO}_{2}$ nanoparticles were aggregated into nanosized particles (100 nm or less) with a near-sphere shape, which formed a mesoporous structure of $\mathrm{CeO}_{2}$ on the GFC. Figure 3(d) shows the $\mathrm{N}_{2}$ adsorption/desorption isotherms of the $\mathrm{HCO} / \mathrm{GFC}$ adsorbent, where $P$ is the partial pressure of nitrogen and $P_{0}$ is the saturated vapor pressure of nitrogen at adsorption temperature. The $\mathrm{N}_{2}$ adsorption followed the lower curve and the $\mathrm{N}_{2}$ desorption followed the upper curve. From its isotherms, the BrunauerEmmett-Teller (BET) specific surface area of the $\mathrm{HCO} / \mathrm{GFC}$ adsorbent could be determined at $\sim 184$ $\mathrm{m}^{2} / \mathrm{g}$. The inset image in Fig. 3(d) shows the pore size distribution of the HCO/GFC adsorbent, where $D_{\mathrm{v}}(d)$ represents the change of pore volume with different pore diameters. It is clearly demonstrated that most pores were mesoporous with an average pore diameter of $\sim 37 \mathrm{~nm}$. Thus, the arsenic contaminated water could 

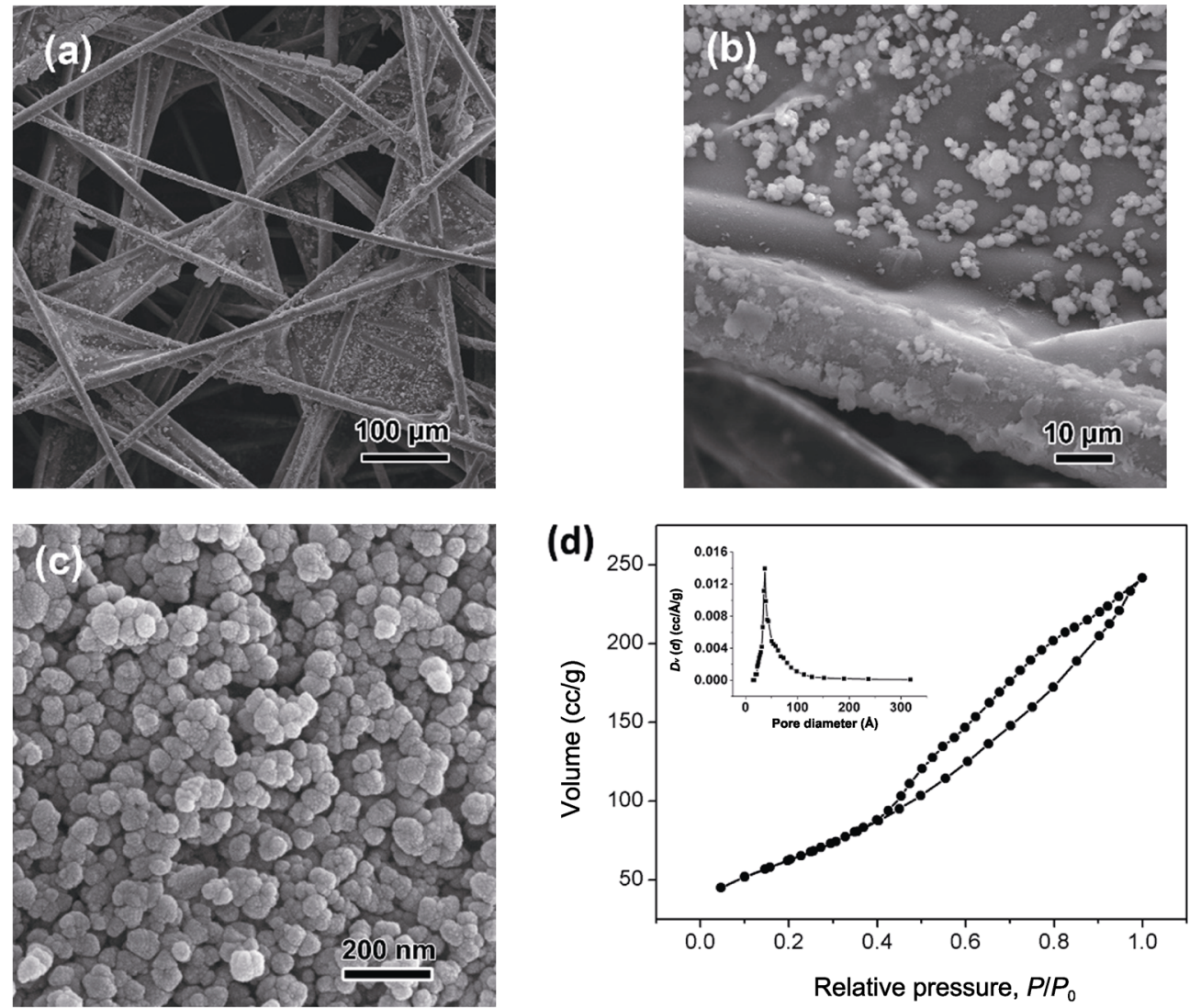

Fig. 3 (a) FESEM image of the HCO/GFC adsorbent. (b) FESEM image of the HCO/GFC adsorbent with a higher magnitude. (c) FESEM image of $\mathrm{HCO}$ nanoparticles. (d) $\mathrm{N}_{2}$ adsorption/desorption isotherms of the $\mathrm{HCO} / \mathrm{GFC}$ adsorbent (note: the inset image shows its pore size distribution).

have a good contact with the active $\mathrm{CeO}_{2}$ surface efficiently for the removal of arsenic species from their adsorption onto hydrous $\mathrm{CeO}_{2}$ nanoparticles immobilized on the GFC.

\section{2 Arsenic adsorption capacity of the HCO/GFC adsorbent}

Due to the toxic nature of arsenic, the MCLs for arsenic in both drinking water and safe contact water are both set at $10 \mu \mathrm{g} / \mathrm{L}$ [2]. Thus, the arsenic amount that an adsorbent could adsorb at low equilibrium concentration should have more practical significance than its maximum adsorption capability under very high equilibrium concentration for the estimation of its performance in arsenic removal practice. Figure 4(a) demonstrates the amount of arsenic adsorbed by HCO nanoparticles at low equilibrium arsenic concentration with the solution $\mathrm{pH}$ at $\sim 7$. The adsorption data of both $\mathrm{As}(\mathrm{III})$ and $\mathrm{As}(\mathrm{V})$ could be best fitted with the Freundlich isotherm as given in Eq. (3):

$$
q_{\mathrm{e}}=K_{\mathrm{F}} C_{\mathrm{e}}^{\frac{1}{n}}
$$

where $q_{\mathrm{e}}$ is the amount of As adsorbed at equilibrium $(\mathrm{mg} / \mathrm{g}), C_{\mathrm{e}}$ is the equilibrium arsenic concentration in water samples (mg/L), and $K_{\mathrm{F}}$ and $n$ are the Freundlich constants. When the equilibrium arsenic concentration was $\sim 10 \mu \mathrm{g} / \mathrm{L}$, the adsorbed arsenic amount of the $\mathrm{HCO}$ adsorbent for $\mathrm{As}(\mathrm{III})$ and $\mathrm{As}(\mathrm{V})$ were $\sim 5$ and $\sim 4 \mathrm{mg} / \mathrm{g}$, and the HCO adsorbent generally demonstrated a better adsorption capability on the more mobile and toxic As(III) than on As(V). Usually, As(III) could not have high affinity to traditional adsorbents compared with charged $\mathrm{As}(\mathrm{V})$ due to its existence as nonionic $\mathrm{H}_{3} \mathrm{AsO}_{3}$ in natural water at near neutral $\mathrm{pH}$ environment [26]. The good adsorption of both As(III) and As(V) by the HCO adsorbent could eliminate the pre-treatment required by traditional arsenic adsorbents, which could largely simplify the arsenic removal process and lower the treatment cost. Table 2 compares the adsorption capabilities of some traditional arsenic adsorbents reported in Refs. [14,27,28] with that of the HCO adsorbent at near neutral $\mathrm{pH}$ environment. Usually, the As(III) adsorption capability was not reported in literature on these traditional arsenic adsorbents due to 

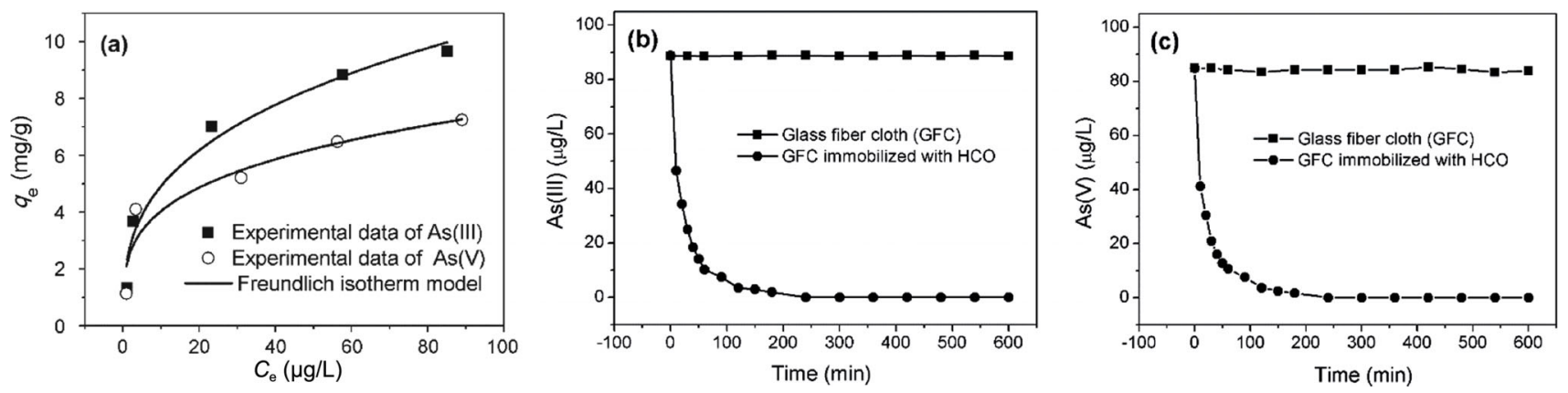

Fig. 4 (a) Equilibrium adsorption isotherms of $\mathrm{As}(\mathrm{III})$ and $\mathrm{As}(\mathrm{V})$ on $\mathrm{HCO}$ nanoparticles with low equilibrium concentrations. (b, c) Adsorption kinetics of As(III) (the initial As(III) concentration $\left.C_{0}=84 \mu \mathrm{g} / \mathrm{L}\right)$ and $\mathrm{As}(\mathrm{V})\left(C_{0}=89 \mu \mathrm{g} / \mathrm{L}\right)$ on the GFC and the $\mathrm{HCO} / \mathrm{GFC}$ adsorbent, respectively.

Table 2 Performance of various adsorbents at low equilibrium arsenic concentrations

\begin{tabular}{cccccc}
\hline \multirow{2}{*}{ Adsorbent } & \multirow{2}{*}{ Surface area $\left(\mathrm{m}^{2} / \mathrm{g}\right)$} & $\mathrm{pH}$ & Sorbate & \multicolumn{2}{c}{ Sorption capacity $(\mathrm{mg} / \mathrm{g})$} \\
\cline { 5 - 6 } & & & & $C_{\mathrm{e}}=10 \mathrm{ppb}$ & $C_{\mathrm{e}}=50 \mathrm{ppb}$ \\
\hline Ferric hydroxide & $240-300$ & 6.5 & $\mathrm{As}(\mathrm{V})$ & 1.1 & 1.4 \\
Aminated fiber & - & 7.0 & $\mathrm{As}(\mathrm{V})$ & 1.7 & - \\
$\mathrm{ZrO}_{2}$ sphere & 32 & 7.3 & $\mathrm{As}(\mathrm{V})$ & 0.7 & 1.1 \\
\hline
\end{tabular}

their lack of affinity to As(III) at near neutral $\mathrm{pH}$ environment. From the comparison, it was clear that the HCO adsorbent had a superior arsenic adsorption performance on both $\mathrm{As}(\mathrm{III})$ and $\mathrm{As}(\mathrm{V})$ than these traditional arsenic adsorbents.

Figures 4(b) and 4(c) show the As(III) and As(V) adsorption performances of the HCO/GFC adsorbent, respectively, compared with that of the pure GFC without HCO loading. The initial As(III) and As(V) concentrations were $\sim 84$ and $\sim 89 \mu \mathrm{g} / \mathrm{L}$, respectively, which were in the high end level of arsenic contamination in drinking water. The experiments were conducted in a batch reactor with the solution $\mathrm{pH}$ at $\sim 7$ and the adsorbent loading of $0.1 \mathrm{~g} / \mathrm{L}$. The results clearly showed that the pure GFC without HCO loading had no arsenic adsorption capability, whereas the $\mathrm{HCO} / \mathrm{GFC}$ adsorbent demonstrated a good arsenic adsorption performance for both $\mathrm{As}(\mathrm{III})$ and $\mathrm{As}(\mathrm{V})$. After $120 \mathrm{~min}$, the arsenic adsorption by the $\mathrm{HCO} / \mathrm{GFC}$ adsorbent reached a plateau for either $\mathrm{As}(\mathrm{III})$ or $\mathrm{As}(\mathrm{V})$, and the corresponding equilibrium $\mathrm{As}(\mathrm{III})$ and $\mathrm{As}(\mathrm{V})$ concentrations were reduced to $\sim 8.3$ and $\sim 4 \mu \mathrm{g} / \mathrm{L}$, respectively, which were both within the MCL of arsenic in drinking water. These results suggested that $\mathrm{HCO}$ nanoparticles in the $\mathrm{HCO} / \mathrm{GFC}$ adsorbent acted as the active component for arsenic removal as we designed and the GFC served as the supporting matrix to immobilized HCO nanoparticles and facilitate the flow-through of arsenic contaminated water with low pressure drop during water treatment process.

\section{3 Kinetic model fitness evaluation of arsenic adsorption on the HCO/GFC adsorbent}

In a solid-liquid system, the adsorption kinetics could be commonly fitted with both the pseudo-first-order and pseudo-second-order kinetic models [29-32]. In order to evaluate the fitness of these two adsorption kinetic models on arsenic adsorption on the HCO/GFC adsorbent, kinetic tests were carried out with a series of the $\mathrm{HCO} / \mathrm{GFC}$ adsorbent dosages $(0.1,0.5,1.0$, and $1.5 \mathrm{~g} / \mathrm{L})$ in a representative $500 \mathrm{~mL}$ arsenic aqueous solution with the initial concentrations of $\sim 124 \mu \mathrm{g} / \mathrm{L}$ for $\mathrm{As}(\mathrm{III})$ and $\sim 91 \mu \mathrm{g} / \mathrm{L}$ for $\mathrm{As}(\mathrm{V})$ at $\mathrm{pH} \approx 7$ as shown in Figs. S1(a) and S1(b) in the Electronic Supplementary Material (ESM), respectively. The kinetic experimental data were further fitted with both the pseudo-first-order and pseudo-second-order kinetic models as shown in Fig. S2 in the ESM for As(III) adsorption and Fig. S3 in the ESM for As(V) adsorption, respectively. Figures 5(a) and 5(b) show the relationship between the adsorbent dosage and the corresponding correlation coefficient $\left(R^{2}\right)$ data for $\mathrm{As}(\mathrm{III})$ adsorption and $\mathrm{As}(\mathrm{V})$ adsorption with both models, respectively. It clearly demonstrated that with the increase of the adsorbent loading, the $R^{2}$ of the pseudo-first-order model fitting gradually increased towards 1 , while the $R^{2}$ of the pseudo-second-order model fitting gradually decreased away from 1 . Thus, the fitness of kinetic models changed with the increase of the adsorbent loading. When the adsorbent loading 

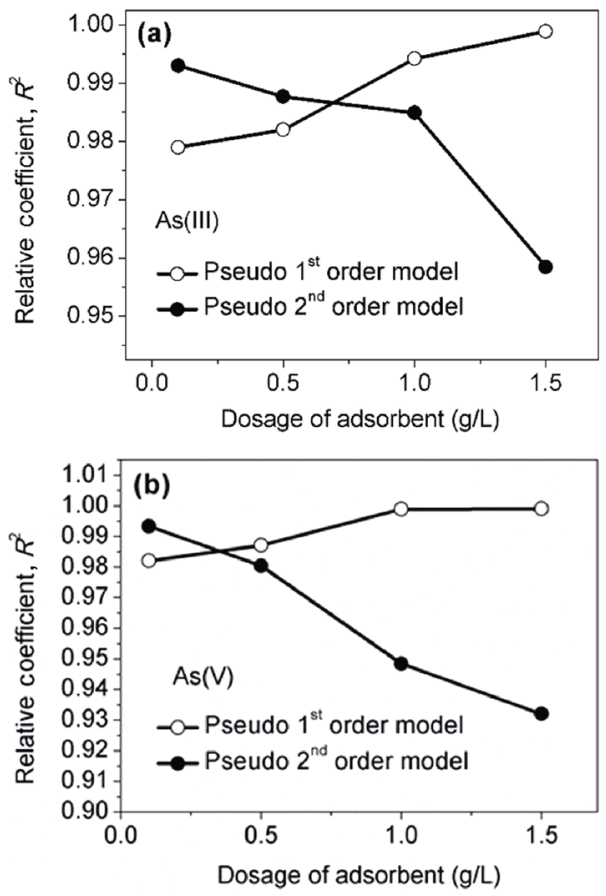

Fig. 5 Correlation coefficients $\left(R^{2}\right)$ of the pseudo-firstorder and the pseudo-second-order kinetics models with four different adsorbent dosages for (a) As(III) adsorption and (b) $\mathrm{As}(\mathrm{V})$ adsorption.

was relatively low, the pseudo-second-order model could fit the kinetic experimental data better, whereas the pseudo-first-order model could fit the kinetic experimental data better when the adsorbent loading amount was over $\sim 0.6 \mathrm{~g} / \mathrm{L}$ for As(III) and $\sim 0.3 \mathrm{~g} / \mathrm{L}$ for $\mathrm{As}(\mathrm{V})$, respectively.

With the increase of the adsorbent loading in the arsenic solution of the same volume, the ratio of adsorbent to arsenic species increased and there could be sufficient surface adsorption site to adsorb arsenic species even in the later stage of the adsorption process. Thus, a fast adsorption kinetics should be observed and a low exponential rate equation (pseudo-first-order kinetic model) should be more suitable to describe it. On the contrary, if the adsorbent loading was small, the ratio of adsorbent to arsenic species was relatively low, and the already adsorbed arsenic species could occupy a considerable part of active sites on the surface of hydrous $\mathrm{CeO}_{2}$ nanoparticles. Thus, arsenic species had to overcome the diffusion resistance to adsorb onto the inner pores of the hydrous $\mathrm{CeO}_{2}$ nanoparticle agglomerates in the later stage of the adsorption process. Then, the intraparticle diffusion could be the limiting mass transfer step and control the adsorption kinetics [29]. So the adsorption rate in the later stage of the adsorption process would decrease, and a high exponential rate equation (pseudo-second-order kinetic model) should be more suitable to describe it. This analysis was clearly consistent with the experimental data shown in Figs. 5(a) and 5(b).

\section{4 Chemical states of arsenic species on the HCO/GFC adsorbent}

Figure 6 shows the high-resolution XPS scans over As $3 \mathrm{~d}$ peak on the $\mathrm{HCO} / \mathrm{GFC}$ adsorbent surface after the $\mathrm{As}(\mathrm{III})$ and $\mathrm{As}(\mathrm{V})$ adsorptions, respectively. Both the $\mathrm{As}(\mathrm{III})-\mathrm{HCO} / \mathrm{GFC}$ sample and As(V)-HCO/GFC sample demonstrated a single peak for As $3 \mathrm{~d}$. The binding energy of $\mathrm{As}(\mathrm{III})-\mathrm{HCO} / \mathrm{GFC}$ was $\sim 44.1 \mathrm{eV}$, and the binding energy of $\mathrm{As}(\mathrm{V})-\mathrm{HCO} / \mathrm{GFC}$ was $\sim 45.2 \mathrm{eV}$. It had been reported in literature that the binding energy of $\mathrm{As}(\mathrm{V}) 3 \mathrm{~d}$ adsorbed on $\mathrm{CuO}$ was at $\sim 45.2 \mathrm{eV}$ and the binding energy of As(III) $3 \mathrm{~d}$ was usually about $1 \mathrm{eV}$ lower than that of $\mathrm{As}(\mathrm{V})[33,34]$. Thus, it could be concluded that the oxidation states of both As(III) and $\mathrm{As}(\mathrm{V})$ did not change after their adsorptions onto the $\mathrm{HCO} / \mathrm{GFC}$ adsorbent surface, and the removal of arsenic species from water by the $\mathrm{HGO} / \mathrm{GFC}$ adsorbent mainly involved the adsorption process.

\section{5 Continuous flow column tests of the HCO/GFC cartridge with lab-prepared arsenic solutions}

Continuous flow column tests of the $\mathrm{HCO} / \mathrm{GFC}$ cartridge were conducted firstly with lab-prepared As(III) and $\mathrm{As}(\mathrm{V})$ solutions of a series of $\mathrm{pH}$ values, respectively, to examine its arsenic removal performance for potential applications. Figures 7(a) and 7(b) show the breakthrough curves of $\mathrm{As}(\mathrm{III})$ and $\mathrm{As}(\mathrm{V})$, respectively. The initial As(III) concentration was $\sim 84 \mu \mathrm{g} / \mathrm{L}$, the initial As(V) concentration was $\sim 89 \mu \mathrm{g} / \mathrm{L}$, and the empty bed contact time $(\mathrm{EBCT})$ was fixed at $4 \mathrm{~min}$. The results demonstrated that the $\mathrm{HCO} / \mathrm{GFC}$ cartridge could

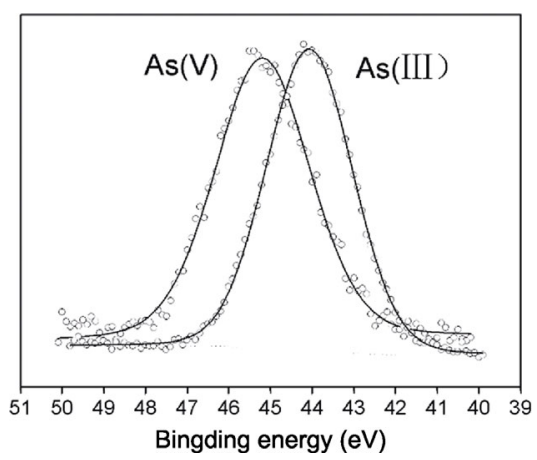

Fig. 6 High-resolution XPS scans on As 3d peak of As(III)-HCO and As(V)-HCO nanoparticles. 

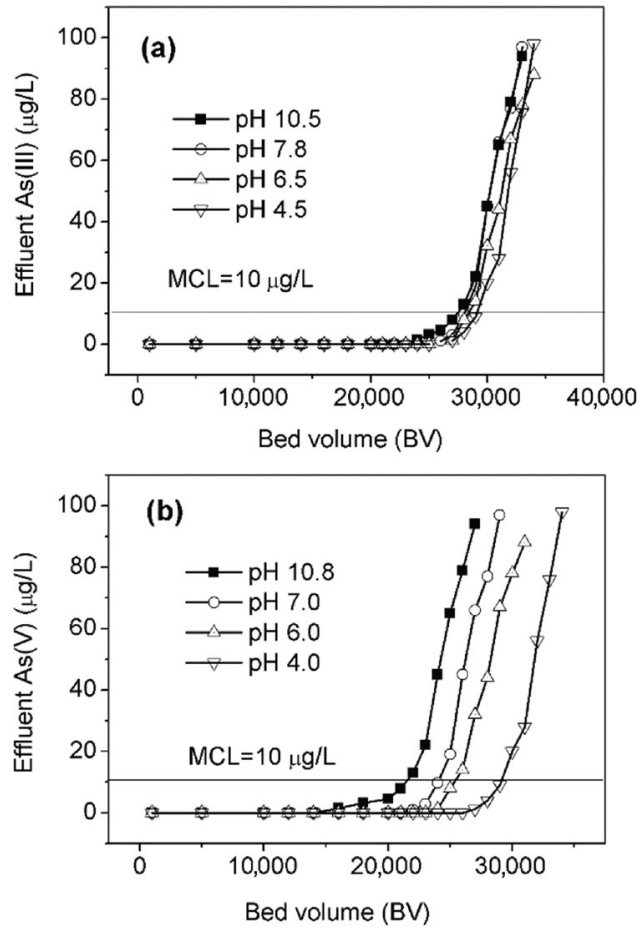

Fig. 7 Arsenic removal of (a) As(III) $\left(C_{0}=84 \mu \mathrm{g} / \mathrm{L}\right)$ and (b) $\operatorname{As}(\mathrm{V})\left(C_{0}=89 \mu \mathrm{g} / \mathrm{L}\right)$ on the $\mathrm{HCO} / \mathrm{GFC}$ adsorbent at different $\mathrm{pH}$ values.

successfully remove both As(III) and As(V) well below the MCL of arsenic species in drinking water $(10 \mu \mathrm{g} / \mathrm{L})$ for large amounts of water compared to its bed volume. When the arsenic concentration in the effluent reached $10 \mu \mathrm{g} / \mathrm{L}$, for example, its breakthrough bed volume (BV) for $\mathrm{As}(\mathrm{III})$ was $\sim 27,000 \mathrm{BV}$ at $\mathrm{pH} 6.5$, and that for $\mathrm{As}(\mathrm{V})$ was $\sim 23,700 \mathrm{BV}$ at $\mathrm{pH} 7.0$. It was found that the $\mathrm{pH}$ dependences of the $\mathrm{HCO} / \mathrm{GFC}$ cartridge to As(III) and $\mathrm{As}(\mathrm{V})$ were different. Figure 7(a) demonstrates that no significant $\mathrm{pH}$ dependence was observed for the As(III) removal performance of the $\mathrm{HCO} / \mathrm{GFC}$ cartridge. When the As(III) solution $\mathrm{pH}$ changed largely from 4.5 to 10.5 , its As(III) breakthrough curves were generally similar and its $\mathrm{As}(\mathrm{III})$ breakthrough bed volume just slightly decreased from $\sim 29,000$ to $\sim 27,000 \mathrm{BV}$. For $\mathrm{As}(\mathrm{V})$, however, the adsorption performance of $\mathrm{HCO} / \mathrm{GFC}$ cartridge demonstrated a clear $\mathrm{pH}$ dependence as shown in Fig. 7(b). When the $\mathrm{As}(\mathrm{V})$ solution $\mathrm{pH}$ changed largely from 4.0 to 10.8, its $\mathrm{As}(\mathrm{V})$ breakthrough bed volume decreased obviously from $\sim 29,000$ to $\sim 21,500 \mathrm{BV}$.

This phenomenon could be related to the difference existence states of $\mathrm{As}(\mathrm{III}) / \mathrm{As}(\mathrm{V})$ and surface charge states of $\mathrm{HCO}$ nanoparticles in water under different $\mathrm{pH}$ conditions. The isoelectric point (IEP) of active HCO nanoparticles for arsenic adsorption was at $\mathrm{pH} \approx 2.7$, and the glass fiber had little effect on the IEP of HCO nanoparticles. For the $\mathrm{pH}$ range we investigated (from 4 to 11), the surface of HCO nanoparticles was negatively charged, and the negative charge increased with the increase of the solution $\mathrm{pH}$. When the As(III) solution $\mathrm{pH}$ was less than 9.2, As(III) existed predominately as non-charged $\mathrm{H}_{3} \mathrm{AsO}_{3}$ [35], and no repulsive force existed between the negatively-charged HCO nanoparticle surface and As(III) or adsorbed As(III) and As(III) still in water. Only when the As(III) solution $\mathrm{pH}$ was over 9.2, $\mathrm{As}$ (III) existed mainly as $\mathrm{H}_{2} \mathrm{AsO}_{3}{ }^{-}$and now the negatively-charged $\mathrm{HCO}$ nanoparticle surface could begin to have the coulomb repulsive force to As(III) to induce the observed slight decrease of the As(III) removal performance of the $\mathrm{HCO} / \mathrm{GFC}$ cartridge. When the $\mathrm{As}(\mathrm{V})$ solution $\mathrm{pH}$ value was at $(\sim 4)-(\sim 11), \mathrm{As}(\mathrm{V})$ existed mainly in the forms of $\mathrm{H}_{2} \mathrm{AsO}_{4}^{-}$and $\mathrm{HAsO}_{4}^{2-}$. Thus, there always existed an electric repulsion between $\mathrm{As}(\mathrm{V})$ and the negative-charged HCO nanoparticle surface, and the repulsion increased with the increase of the solution $\mathrm{pH}$. Furthermore, the adsorption of these negatively-charged $\mathrm{As}(\mathrm{V})$ species could also cause the coulomb repulsive effect between adsorbed As $(\mathrm{V})$ and $\mathrm{As}(\mathrm{V})$ still in water. Thus, the $\mathrm{As}(\mathrm{V})$ removal performance of the $\mathrm{HCO} / \mathrm{GFC}$ cartridge continued to decrease with the increase of the solution $\mathrm{pH}$.

\section{6 Continuous flow column tests of the HCO/GFC cartridge with natural water}

To examine the arsenic removal performance of the $\mathrm{HCO} / \mathrm{GFC}$ cartridge in the real water body environment, continuous flow column tests were conducted on it with an arsenic-contaminated natural water sample from Yangzong Lake (China), which was contaminated by industrial pollution. Table 1 summarizes the water quality data of the natural water sample. It demonstrated that various ion species existed in the natural water sample with concentrations much higher than that of arsenic species (total arsenic concentration of $\sim 65 \mathrm{ppb}$ ), which could have strong competition effects on the arsenic removal performance of the $\mathrm{HCO} / \mathrm{GFC}$ cartridge. Figure 8(a) shows the breakthrough curves of the total arsenic species in the natural water sample with a series of EBCTs of 2, 4, and $6 \mathrm{~min}$, respectively, which demonstrated that the $\mathrm{HCO} / \mathrm{GFC}$ cartridge had a very good arsenic removal performance even for the treatment of arsenic-contaminated natural water. For EBCTs of 2, 4, and $6 \mathrm{~min}$, the arsenic breakthrough bed volumes of 

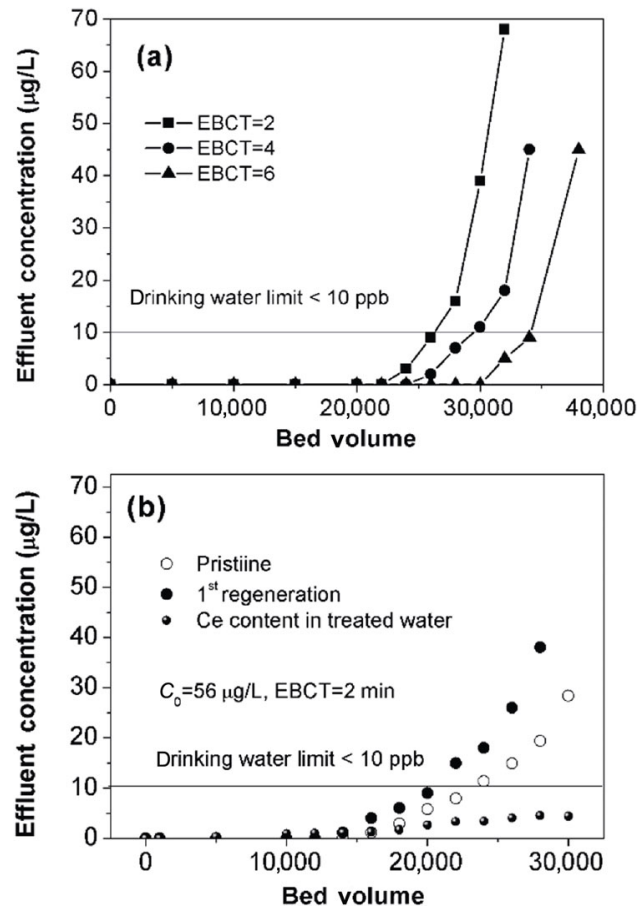

Fig. 8 (a) Column test of the HCO/GFC adsorbent with natural water from Yangzong Lake (China). (b) Regeneration performance and Ce content examination in the treated water effluent during the continuous flow column test of the $\mathrm{HCO} / \mathrm{GFC}$ adsorbent.

the $\mathrm{HCO} / \mathrm{GFC}$ cartridge were $\sim 24,000, \sim 30,000$, and $\sim 33,000 \mathrm{BV}$, respectively, when the arsenic concentration in the effluent reached $10 \mu \mathrm{g} / \mathrm{L}$. The arsenic breakthrough bed volume of the $\mathrm{HCO} / \mathrm{GFC}$ cartridge decreased with the decrease of EBCT as expected, which could be attributed to the less contact time effect.

The regeneration and reuse of an arsenic adsorbent are critical for its potential applications. After the arsenic concentration in the effluent reached $10 \mu \mathrm{g} / \mathrm{L}$, the $\mathrm{HCO} / \mathrm{GFC}$ cartridge was disassembled from the flow-through apparatus, soaked in $0.1 \mathrm{M} \mathrm{NaOH}$ aqueous solution for $2 \mathrm{~h}$ for arsenic desorption, washed by DI water for several times until the water $\mathrm{pH}$ reached $\sim 7$, and reassembled into the flow-through apparatus for the next continuous flow column test. Figure $8(\mathrm{~b})$ compares the breakthrough curves of the total arsenic species in the natural water sample with EBCT of 2 min for the pristine $\mathrm{HCO} / \mathrm{GFC}$ cartridge and the $\mathrm{HCO} / \mathrm{GFC}$ cartridge after one time regeneration. When the arsenic concentration in the effluent reached $10 \mu \mathrm{g} / \mathrm{L}$, the arsenic breakthrough bed volume of the pristine $\mathrm{HCO} / \mathrm{GFC}$ cartridge was $\sim 24,000 \mathrm{BV}$, while that after its first-time regeneration was $\sim 20,500$ BV. From this comparison, the $\mathrm{HCO} / \mathrm{GFC}$ cartridge retained over
$85 \%$ of its original arsenic removal performance after regeneration. Thus, it could be regenerated and reused to remove arsenic species from contaminated natural water efficiently, which could largely reduce the material cost for apparatus based on the HCO/GFC cartridge and be beneficial for its potential applications.

The concentration of cerium in the effluent was also examined during the continuous flow column test with the arsenic-contaminated natural water sample to evaluate the stability of the $\mathrm{HCO} / \mathrm{GFC}$ adsorbent during the long time operation. Figure 8(b) shows the Ce content in the treated water effluent during the continuous flow column test for the natural water sample with EBCT of 2 min. It was always lower than $5 \mathrm{ppb}$ during the whole treatment process, which showed that the $\mathrm{HCO} / \mathrm{GFC}$ cartridge was stable in water and its use as the arsenic adsorbent did not cause secondary pollution to drinking water. These arsenic removal experiments with arsenic contaminated natural water samples showed that the $\mathrm{HCO} / \mathrm{GFC}$ cartridge had a good arsenic removal performance in natural water with a large arsenic breakthrough bed volume, high regeneration capability, and good stability, which demonstrated its application potential for drinking water treatment.

\section{Conclusions}

This study offered a low-cost and simple method for the synthesis of hydrous $\mathrm{CeO}_{2}$ nanoparticles attached on glass fiber adsorbents which have good arsenic removal performance and the potential industrial applicability. The HCO/GFC adsorbent was rolled into a cartridge for arsenic removal test. The arsenic removal performance was evaluated by equilibrium adsorption isotherm test, adsorption kinetic test, and flow through column test. The $\mathrm{pH}$ effects on column test were conducted. The test results show that $\mathrm{HCO} / \mathrm{GFC}$ cartridge has the advantages of high arsenic removal capacity, easy handling, and low cost. The more toxic As(III) in water can be easily removed within a wide range of solution $\mathrm{pH}$ without pre-treatment. The arsenic contaminated ground-water from Yangzong Lake (China) was used in the column test. At EBCT of $2 \mathrm{~min}$, the breakthrough bed volume was over 24,000 when the arsenic concentration in the effluent reached $10 \mathrm{ppb}$. The Ce content in the treated water was lower than 5 ppb during the column test, which showed that the use of the HCO/GFC material as an adsorbent did 
not cause secondary pollution. The application conditions of the pseudo-first and pseudo-second models of adsorption kinetics are also clarified. When the ratio of $\mathrm{As} / \mathrm{HCO}$ is low, the low exponential rate equation (first-order equation) is more suitable. When the ratio of As/HCO is higher, the high exponential rate equation (secondary equation) is more suitable.

\section{Acknowledgements}

This study was supported by the National Natural Science Foundation of China (Grant Nos. 51672283 and 51902271), the Fundamental Research Funds for the Central Universities (Grant Nos. A1920502051907-15, 2682020CX07, and 2682020CX08), Sichuan Science and Technology Program (Grant Nos. 2020YJ0259 and 2020YJ0072), Doctoral Research Start-up Fund of Hebei GEO University (Grant No. BQ2019003), Joint fund between Shenyang National Laboratory for Materials Science and State Key Laboratory of Advanced Processing and Recycling of Nonferrous Metals (Grant No. 18LHPY009), and Liaoning Baiqianwan Talents Program.

\section{Electronic Supplementary Material}

Supplementary material is available in the online version of this article at https://doi.org/10.1007/s40145-020-0435-0.

\section{References}

[1] Huling JR, Huling SG, Ludwig R. Enhanced adsorption of arsenic through the oxidative treatment of reduced aquifer solids. Water Res 2017, 123: 183-191.

[2] World Health Organization. Guidelines for Drinking-water Quality. 3rd edn. Geneva: WHO Press, 2008: 306.

[3] Jadhav SV, Bringas E, Yadav GD, et al. Arsenic and fluoride contaminated groundwaters: A review of current technologies for contaminants removal. J Environ Manag 2015, 162: 306-325.

[4] Kim Y, Kim C, Choi I, et al. Arsenic removal using mesoporous alumina prepared via a templating method. Environ Sci Technol 2004, 38: 924-931.

[5] Xu ZC, Li Q, Gao SA, et al. As(III) removal by hydrous titanium dioxide prepared from one-step hydrolysis of aqueous TiCl(4) solution. Water Res 2010, 44: 5713-5721.

[6] Lin S, Lu DN, Liu Z. Removal of arsenic contaminants with magnetic $\gamma-\mathrm{Fe}_{2} \mathrm{O}_{3}$ nanoparticles. Chem Eng J 2012, 211-212: 46-52.

[7] Sun TY, Zhao ZW, Liang ZJ, et al. Efficient As(III) removal by magnetic $\mathrm{CuO}-\mathrm{Fe}_{3} \mathrm{O}_{4}$ nanoparticles through photo-oxidation and adsorption under light irradiation. $J$ Colloid Interface Sci 2017, 495: 168-177.

[8] Reddy KJ, McDonald KJ, King H. A novel arsenic removal process for water using cupric oxide nanoparticles. $J$ Colloid Interface Sci 2013, 397: 96-102.

[9] Cui H, Su Y, Li Q, et al. Exceptional arsenic (III, V) removal performance of highly porous, nanostructured $\mathrm{ZrO}_{2}$ spheres for fixed bed reactors and the full-scale system modeling. Water Res 2013, 47: 6258-6268.

[10] Lata S, Samadder SR. Removal of arsenic from water using nano adsorbents and challenges: A review. $J$ Environ Manag 2016, 166: 387-406.

[11] Zhang L, Qin YH, Chen BZ, et al. Catalytic reduction of $\mathrm{SO}_{2}$ by $\mathrm{CO}$ over $\mathrm{CeO}_{2}-\mathrm{TiO}_{2}$ mixed oxides. Trans Nonferrous Met Soc China 2016, 26: 2960-2965.

[12] Li P, Chen XY, Li YD, et al. A review on oxygen storage capacity of $\mathrm{CeO}_{2}$-based materials: Influence factors, measurement techniques, and applications in reactions related to catalytic automotive emissions control. Catal Today 2019, 327: 90-115.

[13] Ackland K, Coey JMD. Room temperature magnetism in $\mathrm{CeO}_{2}$-A review. Phys Rep 2018, 746: 1-39.

[14] Hristovski KD, Westerhoff PK, Crittenden JC, et al. Arsenate removal by nanostructured $\mathrm{ZrO}_{2}$ spheres. Environ Sci Technol 2008, 42: 3786-3790.

[15] Raichur AM, Jyoti Basu M. Adsorption of fluoride onto mixed rare earth oxides. Sep Purif Technol 2001, 24: 121-127.

[16] Xiao HY, Ai ZH, Zhang LZ. Non aqueous sol-gel synthesized hierarchical $\mathrm{CeO}_{2}$ nanocrystal microspheres as novel adsorbents for wastewater treatment. J Phys Chem C 2009, 113: 16625-16630.

[17] Haron MJ, Ab Rahim F, Abdullah AH, et al. Sorption removal of arsenic by cerium-exchanged zeolite P. Mater Sci Eng: B 2008, 149: 204-208.

[18] Peng XJ, Luan ZK, Ding J, et al. Ceria nanoparticles supported on carbon nanotubes for the removal of arsenate from water. Mater Lett 2005, 59: 399-403.

[19] Xu WH, Wang J, Wang L, et al. Enhanced arsenic removal from water by hierarchically porous $\mathrm{CeO}_{2}-\mathrm{ZrO}_{2}$ nanospheres: Role of surface- and structure-dependent properties. $J$ Hazard Mater 2013, 260: 498-507.

[20] Li RH, Li Q, Gao SA, et al. Exceptional arsenic adsorption performance of hydrous cerium oxide nanoparticles: Part A. Adsorption capacity and mechanism. Chem Eng $J$ 2012, 185-186: 127-135.

[21] Suzuki TM, Bomani JO, Matsunaga H, et al. Preparation of porous resin loaded with crystalline hydrous zirconium oxide and its application to the removal of arsenic. React Funct Polym 2000, 43: 165-172.

[22] Sun WZ, Li Q, Gao SA, et al. Exceptional arsenic adsorption performance of hydrous cerium oxide nanoparticles: Part B. Integration with silica monoliths and dynamic treatment. Chem Eng J 2012, 185-186: 136-143.

[23] Chen JH, Liu PS, Cheng W. PBA-loaded albite-base 
ceramic foam in application to adsorb harmful ions of $\mathrm{Cd}$, Cs and As(V) in water. Multidiscip Model Mater Struct 2019, 15: 659-672.

[24] Liu PS, Cui G, Guo YJ, et al. A novel sort of porous ceramic foam ball with modified surface for arsenic removal from aqueous solution. J Iron Steel Res Int 2017, 24: 661-668.

[25] Padungthon S, Li JZ, German M, et al. Hybrid anion exchanger with dispersed zirconium oxide nanoparticles: A durable and reusable fluoride-selective sorbent. Environ Eng Sci 2014, 31: 360-372.

[26] Smedley PL, Kinniburgh DG. A review of the source, behaviour and distribution of arsenic in natural waters. Appl Geochem 2002, 17: 517-568.

[27] Banerjee K, Amy GL, Prevost M, et al. Kinetic and thermodynamic aspects of adsorption of arsenic onto granular ferric hydroxide (GFH). Water Res 2008, 42: 3371-3378.

[28] Deng SB, Yu G, Xie SH, et al. Enhanced adsorption of arsenate on the aminated fibers: Sorption behavior and uptake mechanism. Langmuir 2008, 24: 10961-10967.

[29] Suresh Kumar P, Korving L, Keesman KJ, et al. Effect of pore size distribution and particle size of porous metal oxides on phosphate adsorption capacity and kinetics. Chem Eng J 2019, 358: 160-169.

[30] Ho YS, McKay G. The sorption of lead(II) ions on peat. Water Res 1999, 33: 578-584.

[31] Ho Y, McKay G. The kinetics of sorption of divalent metal ions onto sphagnum moss peat. Water Res 2000, 34:
$735-742$.

[32] Ho YS, McKay G. Pseudo-second order model for sorption processes. Process Biochem 1999, 34: 451-465.

[33] Martinson CA, Reddy KJ. Adsorption of arsenic (III) and arsenic (V) by cupric oxide nanoparticles. J Colloid Interface Sci 2009, 336: 406-411.

[34] Zhang Y, Yang M, Dou XM, et al. Arsenate adsorption on an $\mathrm{Fe}-\mathrm{Ce}$ bimetal oxide adsorbent: Role of surface properties. Environ Sci Technol 2005, 39: 7246-7253.

[35] Goldberg S, Johnston CT. Mechanisms of arsenic adsorption on amorphous oxides evaluated using macroscopic measurements, vibrational spectroscopy, and surface complexation modeling. J Colloid Interface Sci 2001, 234: 204-216.

Open Access This article is licensed under a Creative Commons Attribution 4.0 International License, which permits use, sharing, adaptation, distribution and reproduction in any medium or format, as long as you give appropriate credit to the original author(s) and the source, provide a link to the Creative Commons licence, and indicate if changes were made.

The images or other third party material in this article are included in the article's Creative Commons licence, unless indicated otherwise in a credit line to the material. If material is not included in the article's Creative Commons licence and your intended use is not permitted by statutory regulation or exceeds the permitted use, you will need to obtain permission directly from the copyright holder.

To view a copy of this licence, visit http://creativecommons. org/licenses/by/4.0/. 